\title{
Consequences of 2.4-2.48 Ghz non-ionizing radiation of Wi-Fi router devices on the information processing speed in adolescents.
}

\author{
Kourosh Bamdad $^{1}$, Abdolhasan Shakiba ${ }^{1}$, Masoomeh Esmaeili ${ }^{2 *}$ \\ 1Department of Biology, Payame Noor University (PNU), Iran \\ 2Department of Psychology, Payame Noor University (PNU), Iran
}

\begin{abstract}
Background: In order to investigate possible consequences of radiofrequency electromagnetic radiations of Wi-Fi modem devices on the information processing speed of university students, six hundred teenagers (14-17 years old) selected by cluster random sampling. They further classified into two groups consisting one control group (without Wi-Fi modem at home; $n=200$ ) and experimental group (with Wi-Fi modem at home; $\mathbf{n}=\mathbf{4 0 0}$ ).

Methods: By means of reaction time machine and KDT test, the speed of information processing was examined.

Results: According to our analyses, a significant decrease in the reaction time could be detected in WiFi modem users. The results also revealed that a significant correlation between the uses of Wi-Fi modems with the speed of information processing exists.

Conclusion: In conclusion, it has been demonstrated that the everyday radiofrequency electromagnetic field emitted by Wi-Fi devices has the ability to affect the normal functioning of young people's brain.
\end{abstract}

Keywords Brain functionality; Radiofrequency radiation; Reaction time; Speed of information processing; Wi-Fi

Accepted date: January 08, 2018

\begin{abstract}
Abbreviations
RF-EMFs: Radiofrequency Electromagnetic Fields; IARC: International Agency for Research on Cancer; WHO: World Health Organization; WCDMA: Wideband Code Division Multiple Access; EHS: Electromagnetic Hypersensitivity; PET: Positron Emission Tomography; VGCCs: Voltage-Gated Calcium Channel Activation
\end{abstract}

\section{Introduction}

In recent years, concerns about exposure of individuals to radiofrequency electromagnetic fields (RF-EMFs) generated by wireless devices which cause possible health consequences has been raised, meanwhile, the benefits of wireless networks technologies cannot be overlooked in daily life $[1,2]$.

Human brain and peripheral nervous system is the main target for the frequency from electromagnetic fields (EMFs). Public concerns, regarding both physical and mental complications caused by being exposed to EMFs, have been increased. In 2011, the International Agency for Research on Cancer (IARC) of World Health Organization (WHO), classified EMFs as a group 2B, defines as a possible human carcinogens. Also, the Council of Europe has proposed restrictions on the Internet access and cell phone usage in all schools to protect the teenagers from potentially harmful EMFs [3].

So far, few studies have explored the effect of EMFs on brain functions [4-8]. In addition, many studies reported neuropsychiatric effect of EMFs [9-12]. In a study by Mortazavi et al. [13] a significant association between cordless phone usage and headache, fatigue, difficulties in concentration, nervousness, attention disorders, palpitation, myalgia and tinnitus are reported. Another study indicated a strong association of increased headache, depression and sleep disorder with number and duration of the cell phone and cordless phone calls in a group of the 15 to 19 years old individuals in New Zealand [14]. Kwon et al. [15] investigated the possible health effects of EMFs emitted by wideband code division multiple access (WCDMA) mobile phones in humans. In their work, two groups of self-reported electromagnetic hypersensitivity (EHS) and non-EHS volunteers were investigated for physiological symptoms (heart rate, heart rate variability, and respiratory rate) and eight subjective symptoms. However, from that study they did not conclude any significant physiological changes or subjective symptoms in either group by EMFs generated by WCDMA [15]. In contrast, Volkow et al. [16] used a Positron Emission Tomography (PET) to measure the glucose metabolism in healthy individuals once exposed to cell phone emissions and when not exposed, and demonstrated significantly enhanced glucose metabolism in the regions of brain in the proximity to cell phone antenna. This is interesting because in diseases such as bipolar and depressive disorders and schizophrenia, increasing evidence is showing a relationship between glucose metabolism, mitochondrial dysfunction and such mental diseases [17-19].

Non-thermal effects of EMFs as the main mechanism of EMFs are stemmed from voltage-gated calcium channel activation (VGCCs). These effects largely develop in the brain and peripheral nervous system and cause neuropsychiatric effects. Nitric oxide production, cGMP synthesis and Protein Kinase activation are shown to subsequently result from VGCC. EMFs play a role in the release of neurotransmitters from the brain 
cells and release of hormones by neuroendocrine cells with central role of calcium signalling [20]. Considering the rise in EMFs exposure and its possible neuropsychiatric consequences, this study was conducted regarding the effect of electromagnetic waves emitted from Wi-Fi modems on the speed of information processing of male teens. In this study, we demonstrated a significant association between the usages of Wi-Fi modems and the speed of information processing that is describing in the following lines.

\section{Materials and Methods}

\section{Participants}

The investigation started in year 2016 with600 male high school students (fourteen to seventeen years old range) in Jam city; Bushehr province in Iran. The average age of participants was 16.17 years (SD value was: 1.59). Individuals were elected using clustering sampling method among about 1250 volunteers.

\section{Speed of information processing}

KDT (Coding Test) were used to examine participants' speed of information processing. In the KDT, participants have to solve mental tasks within a short time limit (about $30 \mathrm{~s}$ ). The KDT was originally developed by Lindley et al. [21] using a mixture of letters and digits. The method was further modified by Sitzwohl [22], using figural stimuli as well as separate forms for letters and digits. In the KDT participants should start with No. 1 and then letter A; No. 2 and then B; and so on. In the present study, validity has obtained equal to 89 using test retest method.

\section{Assessment of reaction time}

To evaluate the speed of reaction time, a Japan Jagami reaction time measuring device has been used which comprising the following sections:

1. Main Unit: Includes a box that holds the device on and off. This unit it has keys allowing the test person to select the type of stimulator (visual and audio) as well as the choice of presentation method.

2. Excitation display unit: This part contains a box with a display screen and it also has an audio unit for visual and audio stimulation.

3. Manual unit: It has three keys in red, yellow and blue colors, which according to the type of stimulus the subject must select one of the keys. The reliability coefficient of the reaction time machine in this research was calculated to be 0.81 by Cronbach's alpha. This study includes two simple reaction times and a selective reaction time. In the simple reaction time test, when visual stimuli were provided, subjects were asked to respond whenever they saw red on the screen. Also, in the same conditions (simple reaction time); subjects were asked to press the corresponding button when they listened at the 500 $\mathrm{Hz}$ sound when they were listening. However, in the test of the reaction time, three visual stimuli with red, blue and yellow stimuli were presented and the subjects were asked to press each buttonhole by viewing each of them. Also, during the presentation of the audio stimulator, the 500 and $100 \mathrm{~Hz}$ tests were presented and subjects $\mathrm{He}$ was asked to listen to the selected 3-hour response time with a force of 1000 and press the corresponding button sound. The audible and visual response time is stored with the accuracy of one hundredth of a second in the device. Participants in this study first with the test site and how to perform a simple reaction time test or time, the selected reaction was introduced and the test was performed individually. Each participant sat on a chair for a test and handed him on a chair. The front-facing audio and visual acoustic screen and the response screen were placed on the armchair. The participant, by viewing the color or the sound of the sound, pressed the relevant button on the response screen. In total, each participant responded to 60 visual stimuli and 60 audios during a simple and selective response tests.

\section{Wi-Fi measurements}

Information regarding exposure to EMF sources at home was collected using a detailed questionnaire administered to all ostensible healthy males. The questionnaire is composed of questions about the history of using Wi-Fi at home, the average duration of daily use of Wi-Fi routers, and the location of these Wi-Fi modems. Only subjects with fully filled questionnaire were included for further analysis $(n=600)$. In this study, all teenagers, who had no Wi-Fi modem at home were considered as non-users and those teenagers who had Wi-Fi modems at home for more than one year were considered as Wi-Fi users.

\section{Statistical analysis}

SPSS 20.0 (SPSS Inc., Chicago, IL, USA) was used to perform statistical analyses. Student's t test was used for comparison of obtained scores of two different test groups of Wi-Fi users and non-Wi-Fi users. Fisher's exact test was also used to compare different groups based on duration of Wi-Fi usage, and the location of Wi-Fi modems (Table 1). The significance threshold was set at $0.01(p<0.01)$.

Table 1. Summary statistics of enrolled male students.

\begin{tabular}{llll}
\hline Variables & & Frequency & Percentage (\%) \\
\hline Wi-Fi usage & Yes & 400 & 66.7 \\
\cline { 2 - 4 } & No & 200 & 33.3 \\
\hline Cell-phones Wi-Fi & Yes & 496 & 82.7 \\
\hline
\end{tabular}




\begin{tabular}{|c|c|c|c|}
\hline & No & 104 & 17.3 \\
\hline \multirow{4}{*}{ Location of Wi-Fi modems } & Bedroom & 156 & 39.0 \\
\hline & Living room & 210 & 52.5 \\
\hline & Home office & 30 & 7.5 \\
\hline & Kitchen & 4 & 1.0 \\
\hline \multirow{4}{*}{ Duration of $\mathrm{Wi}-\mathrm{Fi}$} & $<1$ year & 28 & 7.0 \\
\hline & $1-2$ years & 190 & 47.5 \\
\hline & $2-3$ years & 162 & 40.5 \\
\hline & 4 years and more & 20 & 5.0 \\
\hline \multirow{3}{*}{ Category of the Internet usage } & Social networks & 250 & 62.5 \\
\hline & Computer games & 106 & 26.5 \\
\hline & Education & 44 & 11 \\
\hline
\end{tabular}

\section{Results}

\section{Speed of information processing results}

The collected data of information processing in high school male teens exposed to EMFs emitted from Wi-Fi modems were analyzed. A clear difference is detected in the speed of information processing results. Based on the results, Wi-Fi users show lower mean values in both reaction time and speed of information processing results (Table 2). However, a high level of significance, $p$-value $=0.002$, between both group of Wi-Fi users and Wi-Fi non-users is determined in speed of information processing results (Table 2).

Table 2. Independent t test of reaction time and the speed of information processing on Wi-Fi users in comparison to non-Wi-Fi users.

\begin{tabular}{|c|c|c|c|c|c|}
\hline Index & & & Wi-Fi users & Non Wi-Fi users & p-value \\
\hline & & & (Mean \pm SD) & (Mean \pm SD) & \\
\hline \multirow[t]{4}{*}{ Reaction time (ms) } & Simple & Visual & $0.81 \pm 0.39$ & $0.587 \pm 0.171$ & 0.015 \\
\hline & & Audio & $0.271 \pm 0.73$ & $0.581 \pm 0.149$ & 0.062 \\
\hline & Selective & Visual & $0.711 \pm 0.253$ & $0.543 \pm 0.167$ & 0.009 \\
\hline & & Audio & $0.849 \pm 0.253$ & $0.719 \pm 0.242$ & 0.11 \\
\hline Speed of information processing & & & $159.33 \pm 20.04$ & $130.66 \pm 6.27$ & $0.002^{*}$ \\
\hline
\end{tabular}

"Statistically significant difference $(p<0.01)$ between the speed of information processing in Wi-Fi users and non-Wi-Fi users

\section{EMF exposure}

The statistical analysis of the collected data is summarized in Table 1. Data showing that $66.7 \%$ of teens were Wi-Fi users and $82.7 \%$ of them are cell-phone users (Table 1 ). In $52.5 \%$ of records Wi-Fi modem are located in living rooms and about $5 \%$ of teens have used home Wi-Fi devices for four years or more (Table 1).

In addition, the results of Fisher's exact test have shown no significant differences in each group based on the predefined criteria as durations defined of Wi-Fi usage, location of Wi-Fi modem and cell-phone usage.

\section{Discussion}

So far numerous studies reported neuropsychiatric effects of EMFs [9-12]. Free radicals activity including oxidative stress is a consequence of exposure to EMFs in biological systems
[23]. However, available reported data do not provide any consistent evidence that EMFs affect biological systems via free radicals mechanisms. For such reasons, EMFs effect on biological systems continues to be a research focus [24]. On the other hand, numerous studies have been focused on the effect of EMFs emitted from Wi-Fi devices on fertility, immune system development, brain development, stress and fetal development [25-28]. Psychological health hazards of exposure to EMFs is another important issue that is explored by many scientists in the field [9-12,29-31]. As age appear to be a probable criterion in determining EMFs effects $[13,31,32]$, we targeted male teenagers in a narrow range of age, i.e., 14-17 year old. We then studied psychologically relevant parameters such as reaction time and speed of information processing. 
Citation: Bamdad $k$, Shakiba A, Esmaeili M. Consequences of 2.4-2.48 Ghz non-ionizing radiation of Wi-Fi router devices on the information processing speed in adolescents. J Psychol Cognition 2018;3(1):1-5.

\section{Conclusion}

Based on our observations, long-term exposure to Wi-Fi radiofrequency radiation caused a significant decrease in reaction time and also speed of information processing of the studied male teenagers. Our study can assist public health policy makers by increase their awareness to potential effects of Wi-Fi usage. Since Wi-Fi usage is not avoidable, more studies are required to investigate its health effect on different age ranges, more importantly childhood and its probable relationships to the people's genders. Fundamental studies are indeed necessary to unravel the potential effect of EMFs exposure on pregnant women and new-borns and young-aged children.

\section{References}

1. Hardell L, Carlberg M, Soderqvist F, et al. Case-control study of the association between malignant brain tumours diagnosed between 2007 and 2009 and mobile and cordless phone use. Int J Oncol. 2013;43:1833-45.

2. Otto $\mathrm{M}$, von Muhlendahl KE. Electromagnetic fields (EMF): Do they play a role in children's environmental health $(\mathrm{CEH})$ ? Int $\mathrm{J}$ Hyg Environ Health. 2007;210:635-44.

3. Watson R. Radiation fears prompt possible restrictions on Wi-Fi and mobile phone use in schools. BMJ. 2011;342.

4. Adibzadeh F, Bakker JF, Paulides MM, et al. Impact of head morphology on local brain specific absorption rate from exposure to mobile phone radiation. Bioelectromagnetics. 2015;36:66-76.

5. Eberhardt JL, Persson BR, Brun AE, et al. Blood-brain barrier permeability and nerve cell damage in rat brain 14 and 28 days after exposure to microwaves from GSM mobile phones. Electromagn Biol Med. 2008;27:215-29.

6. De Gannes FP, Billaudel B, Taxile M, et al. Effects of head-only exposure of rats to GSM-900 on blood-brain barrier permeability and neuronal degeneration. Radiat Res. 2009; 172:359-67.

7. Salford LG, Brun AE, Eberhardt JL, et al. Nerve cell damage in mammalian brain after exposure to microwaves from GSM mobile phones. Environ Health Perspect. 2003;111:881.

8. Shirai T, Imai N, Wang J, et al. Multigenerational effects of whole body exposure to $2.14 \mathrm{GHz}$ W-CDMA cellular phone signals on brain function in rats. Bioelectromagnetics. 2014;35:497-511.

9. Abdel-Rassoul G, El-Fateh OA, Salem MA, et al. Neurobehavioral effects among inhabitants around mobile phone stations. Neurotoxicology. 2007;28:434-40.

10. BortkiewiczA, Gadzicka E, Szyjkowska A, et al. Subjective complaints of people living near mobile phone base stations in Poland. Int J Occup Med Environ Health. 2012;25:31-40.

11. Lamech F. Self-reporting of symptom development from exposure to radiofrequency fields of wireless smart meters in Victoria, Australia: A case series. Altern Ther Health Med. 2014;20:28-39.
12. Eger H, Jahn M. Specific symptoms and radiation from mobile basis stations in Selbitz, Bavaria, Germany: Evidence for dose-effect relationship. Umw Med Ges. 2010;23:130-9.

13. Mortazavi SMJ, Ahmadi J, Shariati M. Prevalence of subjective poor health symptoms associated with exposure to electromagnetic fields among university students. Bioelectromagnetics. 2007;28:326-30.

14. Redmayne M, Smith E, Abramson MJ. The relationship between adolescents' well-being and their wireless phone use: A cross-sectional study. Environ Health. 2013;12:90.

15. Kwon MK, Choi JY, Kim SK, et al. Effects of radiation emitted by WCDMA mobile phones on electromagnetic hypersensitive subjects. Environ Health. 2012;11:69.

16. Volkow ND, Tomasi D, Wang GJ, et al. Effects of cell phone radiofrequency signal exposure on brain glucose metabolism. JAMA. 2011;305:808-13.

17. Hosokawa T, Momose T, Kasai K. Brain glucose metabolism difference between bipolar and unipolar mood disorders in depressed and euthymic states. Prog Neuropsychopharmacol Biol Psychiatry. 2008;33:243-50.

18. Bauer M, Berman S, Stamm S, et al. Levothyroxine effects on depressive symptoms and limbic glucose metabolism in bipolar disorder: A randomized, placebo-controlled positron emission tomography study. Mol Psychiatry. 2016;21:229-36.

19. Scaini G, Rezin GT, Carvalho AF, et al. Mitochondrial dysfunction in bipolar disorder: Evidence, pathophysiology and translational implications. Neurosci Biobehav Rev. 2016;68:694-713.

20. Pall ML. Electromagnetic fields act via activation of voltage-gated calcium channels to produce beneficial or adverse effects. J Cell Mol Med. 2013;17:958-65.

21. Lindley RH, Smith WR, Thomas JT. The relationship between speed of information processing as measured by timed paper-and-pencil tests and psychometric intelligence. Intelligence. 1988;12:17-25.

22. Sitzwohl EM. Konstruktion und U* berpru“fungeinesPapier-Bleistift-Tests zurErfassung von Informations verarbeitungsgeschwindigkeit: Der CodingTest. Unpublished diploma's thesis, University of Graz, Austria.1995.

23. Brocklehurst B, McLauchlan KA. Free radical mechanism for the effects of environmental electromagnetic fields on biological systems. Int J Radiat Biol. 1996;69:3-24.

24. Lacy-Hulbert A, Metcalfe JC, Hesketh R. Biological responses to electromagnetic fields. FASEB J. 1998; 12:395-420.

25. Ait-Aissa S, Billaudel B, De Gannes FP, et al. In situ detection of gliosis and apoptosis in the brains of young rats exposed in utero to a Wi-Fi signal. Comptes Rendus Physique. 2010;11:592-601.

26. Ait-Aissa S, De Gannes FP, Taxile M, et al. In situ expression of heat-shock proteins and 3-nitrotyrosine in brains of young rats exposed to a Wi-Fi signal in utero and in early life. Radiat Res. 2013;179:707-16. 
27. Laudisi F, Sambucci M, Nasta F, et al. Prenatal exposure to radiofrequencies: effects of Wi-Fi signals on thymocyte development and peripheral T-cell compartment in an animal model. Bioelectromagnetics. 2012;33:652-61.

28. Poulletier de Gannes F, Haro E, Hurtier A, et al. Effect of inttero Wi-Fi exposure on the pre-and postnatal development of rats. Birth Defects Res B Dev Reprod Toxicol. 2012;95:130-6.

29. Haarala C, Ek M, Bjornberg L, et al. $902 \mathrm{MHz}$ mobile phone does not affect short term memory in humans. Bioelectromagnetics. 2004;25(6):452-6.

30. Edelstyn N, Oldershaw A. The acute effects of exposure to the electromagnetic field emitted by mobile phones on human attention. Neuroreport. 2002;13:119-21.

31. Lee TM, Lam PK, Yee LT, et al. The effect of the duration of exposure to the electromagnetic field emitted by mobile phones on human attention. Neuroreport. 2003;14:1361-4.

32. Maganioti AE, Papageorgiou CC, Hountala CD, et al. WiFi electromagnetic fields exert gender related alterations on EEG. Paper presented at the 6th International Workshop on Biological Effects of Electromagnetic fields. 2010 .

*Correspondence to:

Masoomeh Esmaeili

Assistant Professor

Department of Psychology

University of Payame Noor University

PO Box 19395-3697

Iran

Tel: $+98(71) 53239040$

E-mail: esmaeilimasomeh@yahoo.com 